\title{
«Nase hoch beim Übersetzen»: Notas acerca de la traducción literaria alemán-español
}

\author{
(«Nase hoch beim Übersetzen»: Notes about \\ German-Spanish literary translation)
}

\author{
M. del Carmen Balbuena Torezano \\ Ir1batom@uco.es \\ Universidad de Córdoba
}

Fecha de recepción: 3 de septiembre de 2013

Fecha de aceptación: 30 de septiembre de 2013

Resumen: El presente trabajo analiza las principales premisas traductológicas propuestas por la traductora ucraniana Swetlana Geier, quien tradujo las cinco grandes obras de Dostojewskij al alemán. La labor del traductor literario, esencialmente compleja, tanto como lo son los textos de partida a los que se enfrenta, se ve reflejada a lo largo del estudio presentado en estas páginas, que aborda la traducción al español de textos líricos y dramáticos alemanes.

Palabras clave: Traducción literaria, Literatura alemana, Traducción, Metodología.

Abstract: This paper aims to analyze the main rules of translation, proposed by the Ukrainian translator Swetlana Geier, who translated the five great novels of Dostojewskij into German. The task of the literary translator is complex, as the source texts he/she handles. The translation activity is reflected along this study that approaches the translation of German lyric and dramatic texts into Spanish.

Key words: Literary Translation, German Literature, Translation, Methodology.

1. «NASE HOCH BEIM ÜBERSETZEN»: LA TRADUCCIÓN LITERARIA Y LA FUNCIÓN DEL TRADUCTOR

Refiriéndose a Fräulein Freimann, su profesora de alemán, la traductora ucraniana Swetlana Geier afirmaba lo siguiente (Gut, 2011: 62): 
Sie hatte vom Übersetzen und von Sprache gar keine Ahnung, aber sie wusste, man darf nicht so übersetzen, dass man am Satz klebt. Man muss so übersetzen, dass man den Blick frei hat. Ich bekam immer zu hören: «Nase hoch beim Übersetzen!» Das heißt, wenn ich übersetzte, durfte ich mich nicht von links nach rechts wie eine Raupe durch die Zeile durchfressen, sonder eben: «Nase hoch beim Übersetzen!» Ich musste so übersetzen, dass ich den Satz zuerst innerlich von mir hattte und inn dann übersetzte, ohne auf das Blatt zu schauen -das, was ich heute mache.

Con estas palabras, y de la forma más contundente, Swetlana Geier establece una de las premisas fundamentales para la traducción literaria: la traducción ha de ser natural, de forma que el texto resultante esté en absoluta sinergia con la lengua y la cultura metas. Para ello, es necesario realizar la traducción "desde dentro", esto es, el traductor ha de hacer suyo el texto, siendo el primer paso la interiorización del mismo, para después poder verterlo a la lengua meta. Sólo así, lejos de lo estrictamente lingüístico y textual, será posible alcanzar una traducción que transmita todos los elementos contenidos en el texto original.

Para la traductora, la traducción es "möglich, aber nur in bestimmten Grenzen" (Gut, 20115: 17). Al ser preguntada sobre esta cuestión, Geier afirma que, a pesar de cuantos teóricos han escrito sobre el proceso traductológico, ella siempre tuvo el convencimiento desde sus inicios como traductora, de que dicho proceso era, en realidad, un proceso deficitario. La razón que esgrime Geier es tan contundente como la primera de sus aseveraciones: porque las lenguas no son compatibles ${ }^{1}$. Amén de la realidad de la diferencia entre las distintas lenguas, existen otros factores, tales como los personales, que la traductora ucraniana denomina "barreras de la personalidad", y que determinan, en definitiva, las distintas posibilidades de la traducción (Gut, $2011^{5}: 117$ y 121):

Die Tatsache, dass die Sprachen nicht kompatibel sind, ist jedoch nicht die einzige Hürde beim Übersetzen. Es gibt auch noch persönliche Hürde beim Übersetzen. Die Grenzen einer Persönlichkeit: Ich bin eine Frau, ich bin eine Russin, ich esse gerne Butter, was weiß ich, ich bin unsportlich, arbeite gern im Garten. Es ist falsch, wenn man sagt, übersetzen ist unmöglich. Das Übersetzen ist möglich, aber nur in bestimmten Grenzen.

(...)

\footnotetext{
${ }^{1}$ A este respecto, afirma Hurtado Albir (2011: 28): "Se traduce porque las lenguas y las culturas son diferentes; la razón de la traducción es, pues, la diferencia lingüística y cultural".
} 
Dieses «Gehäuse», die Persönlichkeit des Übersetzers, ist ebenso bedeutsam wie die Inkongruenz zwischen den Sprachen. Ich übersetze und erlebe das Deutsch als Russin und bin niemals unabhängig davon. Das Bild von Messina ${ }^{2}$ ist ganz besonders schön, weil Hieronymus wie in einer Nussschale sitzt. Ein Fremdkörper iin einem kirchenartigen Raum. So sitze ich in dem Text, den ich verinnerliche, mir ein-verleiben muss. Dass ist so. Und das ist Übersetzen. Und dadurch ist die Neuübersetzung von lebenswichtigen Büchern nicht nur berechtigt, sondern notwendig. Weil man diese Bücher immer wieder haben will. Die Bibel. Den Faust. Verbrechen und Strafe.

Para Geier, la traducción tiene lugar siempre dentro de una "carcasa", de una "Gehäuse", que no es más que el marco que rodea al traductor: en el cuadro de Messina, en el que San Jerónimo se encuentra en su lectorium, en silencio, leyendo, analizando, traduciendo. Se ha descalzado, está sentado en su escritorio, y al fondo del lectorium aparecen tres baldas llenas de libros, algunos abiertos, otros cerrados. Dichas baldas representan las Sagradas Escrituras en hebreo, griego y latín, que fueron traducidas por el Santo y vertidas en la Vulgata. Como San Jerónimo, y según la particular visión de Geier, el traductor sólo puede traducir a partir de las circunstancias personales que lo rodean. Sus vivencias, sus conocimientos, su forma de ser, el lugar donde desempeña su trabajo, su condición intelectual, sexual, sus gustos y aficiones, todo lo que hace de él quien es conforman esa "carcasa" desde la cual, irremediablemente, ha de traducir (Gut, 20115: 121):

Der Übersetzer übersetzt stets und nur im Rahmen seiner biografischen Gegebenheiten. Er kann nicht aus sich aussteigen. Ich kann nicht wie ein Mann übersetzen, auch wenn ich August Vierzehn übersetzt habe. Ich habe dieses Buch aus Trotz übersetzt, um zu beweisen, dass eine Frau ein Kriegsdokument bewältigen kann.

El traductor literario es un lector privilegiado, pues puede tener en sus manos la obra original del autor. Su labor no es sólo traductológica, sino que se trata de una labor artística ${ }^{3}$, dado que ha de producir otra obra de arte (Ette, 1998: 13):

\footnotetext{
${ }^{2}$ Se refiere al cuadro de Antonello da Messina, San Jerónimo en su lectorium. San Jerónimo, patrón de los traductores, aparece en su lectorium, trabajando en silencio. La escena tiene lugar dentro de lo que parece ser una iglesia, por cuyas naves aparecen animales alegóricos de la Biblia, y el león que el Santo domesticó tras arrancarle una astilla de una pata.

${ }^{3}$ A este respecto, afirma Ette (1998: 31): "Literarische Übersetzung wird hier zur kreativsten Form aktiver Rezeption zur interpretativen Anverwandlung und Aneignung ästhetischer Artefakte“.
} 
Dies reiht inn traditionell ein in die Gruppe all jener, die wie Opernsänger, Konzertpianisten, Schauspieler oder Dirigenten einne nachschöpferische künstlerische Tätigkeit ausführen ${ }^{4}$.

No obstante, a este respecto cabría señalar que el traductor es el "sirviente" de dos señores: por una parte, ha de verter las palabras de otro -el autor - a la lengua meta; por otra, ha de hacerlo teniendo en cuenta a un segundo lector implícito - aquel que recibe la obra literaria traducida-, por lo que ha de contemplar todos los aspectos relacionados no sólo con la lengua de dicho lector, sino también aquellos relativos a cuestiones extraliterarias y extralingüísticas ${ }^{5}$.

Tomando como referencia esto que acabamos de afirmar, se hace necesario tener en cuenta lo establecido por Friedrich Schleiermacher $(1813)^{6}$, para quien resulta sumamente complicado plasmar la esencia de la lengua original —el "Geist der Ursprache"- en la traducción, y muy especialmente cuando se trata de una traducción literaria —-denominada por el propio Schleiermacher künstliches Übersetzen, "traducción artística"En el caso de los textos literarios, el autor propone dos métodos de traducción (2011: 22-25):

Entweder der Übersetzer läßt den Schriftsteller möglichst in Ruhe, und bewegt den Leser inm entgegen, oder läßt den Leser möglichst in Ruhe und bewegt den Schriftsteller ihm entgegen. Beide sind so gänzlich von einander verschieden, daß durchhaus einer von beiden so streng als möglich muß verfolgt werden, aus jeder Vermischung aber höchst unzuverlässiges Resultat nothwendig hervorgeht und zu

\footnotetext{
${ }^{4}$ Sobre las claras diferencias profesionales, desde el punto de vista económico, prosigue el autor (1998: 13): "Von diesen unterscheidet inn jedoch, daß er anders als sie nicht ins öffentliche Rampenlicht rückt, sondern im Verborgenen bleibt. Die Tätigkeit des Übersetzens evoziert $\mathrm{n}$ icht von ungefähr ein einsames Arbeiten am Schreibtisch, vielleicht sogar zu nächtlicher Zeit, wenn es dem literarischen Übersetzer beschieden ist, einem besser bezahlten »Brotberuf« nachzugehen. Finanziell geht es dem Literaturübersetzer eher schlecht: Er verdient kaum ein Drittel dessen, was seine seit langem professionalisierten Kollegen, die fachsprachlichen Übersetzer und Dolmetscher für ihre Tätigkeit beanspruchen dürfen. Die meisten literarischen Übersetzer verfügen schon der sozialen Absicherung wegen über einen existenzsichernden Beruf".

${ }^{5}$ Teniendo en cuenta esta y otras realidades en torno al encargo de traducción, afirma Hurtado Albir (2011": 64): "La traducción literaria puede tener diversas finalidades, que dependen del status de la obra literaria (subliteratura, clásicos de la literatura, etc.), del encargo de traducción (para una edición de bolsillo, para una edición bilingüe selecta, etc.) y del destinatario (público infantil, juvenil, culto, etc.)".

6 Schleiermacher, Friedrich: "Ueber die verschiedenen Methoden des Uebersetzens". En: Problem des Uebersetzens. Se trata de un estudio presentado ante la Königliche Akademie der Wissenschaften de Berlín el 24 de junio de 1813 por el autor, en el que intentaba explicar e fin y la dificultad de la traducción, al tiempo que diferenciar entre traducción oral —das Dolmetschen- y traducción escrita — das Übersetzen-.
} 
besorgen ist daß Schriftsteller und Leser sich gänzlich verfehlen (...) Im ersten Fälle nämlich ist der Übersetzer bemüht, durch seine Arbeit dem Leser das Verstehen der Ursprache, das inm fehlt, zu ersetzen (...). Die andere aber, indem sie den Verfasser nicht zeigt, wie er selbst würde übersetzt, sondern wie er ursprünglich als Deutscher deutsch würde geschrieben haben, hat wol schwerlichh einen andern Maaßstab der Vollendung, als wenn man versichern könnte, wenn die deutschen Leser insgesamt sich in Kenner und Zeitgenossen des Verfassers verwandeln ließen, so würde innen das Werk selbst ganz dasselbe geworden sein, was innen jetzt, da der Verfassser sich in einen Deutschen verwandelt hat, die Übersetzung ist. Diese Methode haben offenbar alle diejenigen im Auge, welche sich der Formel bedienen, man solle einen Autor so übersetzen, wie er selbst würde deutsch geschrieben haben ${ }^{7}$.

Sea cual sea el método adoptado por el traductor, es un hecho incuestionable que, como lector consciente que es, el primer paso ha de ser, necesariamente, la recepción del texto original de forma analítica, para llegar a su comprensión total, y traspasar los límites textuales, para, como afirmaba Geier, hacer suyo el texto de partida antes de verterlo a la lengua y a la cultura meta.

\section{LA TRADUCCIÓN AL ESPAÑOL DE TEXTOS LITERARIOS ALEMANES: ALGUNAS REFLEXIONES}

Qué duda cabe de que el primer escollo parte, necesariamente, de la propia naturaleza del texto literario. No es igual traducir una novela, que un drama, o un poema. A lo largo de estas páginas nos ocuparemos de abordar la traducción de textos líricos y dramáticos, dadas las peculiaridades que ambos géneros tienen no sólo desde un punto de vista traductológico, sino también desde la perspectiva del análisis literario.

\subsection{La traducción de textos líricos}

En lo concerniente a los textos literarios, la crítica ha concedido una especial atención a la traducción de textos poéticos ${ }^{8}$, dado que en ellos radica una especial dificultad, pues confluyen elementos tales como la rima, el ritmo, la métrica, etc., amén de los propios del hecho literario (Bassnett, 1998: 57):

\footnotetext{
${ }^{7}$ Texto original reproducido en Scientia Traductionis 9, 2011, pp. 3-70.

${ }^{8}$ Vid. a este respecto los trabajos de Holmes $(1969,1978,1994)$, Holmes, de Haan y Popovic (1970), Lefevere (1975), Popovic (1976), de Baugrande (1978), Etkind (1982), Raffel (1988), Sáez Hermosilla (1987), Naito (1993), Bassnett y Lefevere (1998), Rexheuser (2009), y Helin (2012), entre otros.
} 
A great deal of this literature claims that poetry is something apart, that the poet is possessed of some special essential quality that enables the creation of a superior type of text, the poem.

Esta especial dificultad para traducir textos líricos se pone de manifiesto desde el primer momento en el que se acomete la traducción. La primera decisión importante que ha de tomar el traductor es qué tipo de traducción realizar": ¿traducción poética, o traducción de poesía? Pues, aunque pudieran parecer similares, no se trata de un mismo tipo de traducción. Se puede hacer una "traducción de poesía", esto es, transmitir el sentido del texto original, pero sin pretender conservar ritmo, rima o forma, o bien una "traducción poética", en la cual el producto final será, en la lengua meta, un poema, equivalente al original. No significa esto, sin embargo, que el poema en la lengua de llegada tenga que conservar el mismo ritmo y rima que el original alemán. Sin embargo, en los textos poéticos la forma tiene tal importancia, que el traductor es consciente de que un cambio podría arruinar la traducción, ya que el efecto en el lector español no será idéntico al del original. Ilustramos con la traducción de la primera estrofa del conocido Falkenlied (MF 8,33) de Der von Kürenberg lo que acabamos de exponer:

Ich zôch mir einen valken mêre danne ein jâr. dô ich in gezamete als ich in wolte hân und ich im sin gevidere mit golde wol bewant, er huop sich ûf vil hôhe und vluoc in anderiu lant.

(1) Propuesta de traducción de poesía:

Durante más de un año crié para mí un halcón.

Cuando lo hube domesticado como me placía, y había engalanado con cintas doradas su plumaje levantó el vuelo y surcó el aire hacia otros mundos. ${ }^{10}$

\footnotetext{
${ }^{9}$ Afirma E. Etkind (1982) que existen seis tipos de traducción poética (Hurtado Albir, 2011: 66): "la traducción información, en prosa y sin pretensión artística; la traducción interpretación, relacionada con los estudios históricos y estéticos; la traducción alusión, donde existen algunos criterios estéticos (por ejemplo, se rima algún verso), pero no existe un programa estético definido; la traducción aproximación, donde sí que hay un programa estético pero es parcial (transponer rima sin metro, ritmo sin rima, etcétera); la traducción imitación, que suele darse cuando el traductor es poeta y se expresa libremente; la traducción recreación, que es, según el autor, la verdadera traducción poética ya que, sin ir más allá de los límites del mundo estético del poeta, recrea en verso el conjunto de características del poema original".

${ }^{10}$ Traducción de la autora.
} 
(2) Propuesta de traducción poética:

Más de un año ahora ha que un halcón he criado.

Según mi complacencia bien lo hube de domar.

Con nuevas cintas de oro su plumaje he adornado.

¡En busca de otro trovar hoy alza el vuelo y va!. ${ }^{11}$

No es objetivo del presente trabajo determinar qué tipo de traducción es la más adecuada, ni cuál de ellas será la coincidente con el gusto del lector español. Pero resulta evidente la diferencia entre ambas propuestas traductológicas: mientras que la traducción (1) ofrece un contenido muy próximo al del texto original, pero con un marcado carácter prosaico, en la traducción (2) se ha "recreado" el texto, persiguiendo transmitir la esencia del poema original. Lo esencial aquí, amén de la decisión sobre qué tipo de traducción hacer, es la interiorización del texto a la que aludía Geier. No basta con conocer el alemán medieval —Mittelhochdeutsch-, las características morfosintácticas de este estadio de la lengua alemana; o conocer el sentido exacto que tiene cada uno de los términos del poema - saber qué representa el término valke, "halcón", en este tipo de poemas cortesano-caballerescos, por ejemplo-, o saber en qué circunstancias fue creado el poema, quién era su autor, y todos los detalles propios y ajenos al texto. Interiorizar el texto implica, además, identificarse con la época histórica en la cual se gesta la composición, la labor del trovador o Minnesänger, autor del texto, la función del poema, planificado y creado para divertir al público cortesano, las premisas que rigen el amor cortés, y, finalmente, identificarse con el sujeto lírico del poema: es la mujer quien habla, ella quien lanza una queja lastimera por un amor perdido, amor ficticio y fuertemente estereotipado, que la obliga a admitir un cortejo -el del caballero, el del "halcón"-, a tener ciertas actitudes con respecto a quien demanda su favor -actitudes que son las que quedan reflejadas en la metáfora de la "domesticación del halcón"-, y que no conducen a un amor real, pues una vez cumplida su función, el caballero marchará a otra corte - "a otros mundos"-, para volver a desempeñar su papel ante una nueva dama. Sólo la lectura profunda y la identificación con el sujeto lírico conducirá a una comprensión del texto casi idéntica a la de un receptor alemán, y sólo así será posible, "levantando la nariz del texto", como afirma Geier, recodificar el "sentimiento" del texto original para verterlo a la lengua meta, en este caso, el español.

Algo similar ocurre con el siguiente poema, de Friedrich Schiller, Die Götter Griechenlands, del que extraemos dos estrofas:

\footnotetext{
${ }^{11}$ Traducción de la autora.
} 
Da ihr noch die schöne Welt regieret, An der Freude leichtem Gängelband Selige Geschlechter noch geführet, Schöne Wesen aus dem Fabelland! Ach, da euer Wonnedienst noch glänzte, Wie ganz anders, anders war es da! Da man deine Tempel noch bekränzte, Venus Amathusia!

Wo jetzt nur, wie unsre Weisen sagen, Seelenlos ein Feuerball sich dreht, Lenkte damals seinen goldnen Wagen Helios in stiller Majestät.

Diese Höhen füllten Oreaden, Eine Dryas lebt' in jenem Baum, Aus den Urnen lieblicher Najaden Sprang der Ströme Silberschaum.

(3) Propuesta de traducción de poesía ${ }^{12}$ :

Cuando aún gobernábais el bello universo estirpe sagrada, y conducíais hacia la alegría a los ligeros caminantes, ¡bellos seres del país legendario! Cuando todavía relucía vuestro culto arrebatador, iqué distinto, qué distinto era todo entonces, cuando se adornaba tu templo, Venus Amatusia!

Donde ahora, como dicen nuestros sabios, solo gira una bola de fuego inanimada conducía entonces su carruaje dorado Helios con serena majestad.

Las Oréadas llenaban las alturas, una Dríada vivía en cada árbol de las urnas de las encantadoras Náyades brotaba la espuma plateada del torrente.

\footnotetext{
12 Traducción de D. Innerarity (1994). Fuente: http://www.alcoberro.info/planes/poesiag.htm. [Consultado el 20 agosto de 2013].
} 
(4) Propuesta de traducción poética ${ }^{13}$ :

Cuando aún regíais el bello mundo y bajo liviana dicha tutelábais a las estirpes bienaventuradas ¡bellos seres del país de las hadas! ¡Ah! Cuando vuestra gloria aún fulguraba ¡Cuán distinto, cuán distinto era entonces cuando todos tus templos se engalanaban Venus de Amatos!

Donde ahora, según nuestros sabios hombres gira una bola de fuego sin alma Helios conducía su carro dorado con solemne y con regia majestad. Las oréades regían las alturas, una hamádrida moraba cada árbol, y de las urnas de las dulces náyades brotaba la espuma plateada del río.

De las propuestas (3) y (4) es posible colegir que sólo cuando el traductor entiende cada uno de los versos, la razón de ser de todos ellos, desgranando cada término, y lo que llevan implícito, será posible realizar la traducción del texto de forma adecuada. No basta con conocer toda la terminología relativa a la mitología clásica, —Venus, Helios, oréades, dríades, náyades, etc.-, ni dominar los principales presupuestos de la lírica del Periodo Clásico alemán sino, mediante un proceso de "adueñamiento" o interiorización, identificarse con el sujeto lírico, para entender, el lamento procedente de la profunda sensación de tristeza de quien habla, y que contempla cómo la sociedad ha abandonado la Edad Dorada, la creencia en seres superiores que todo lo regían, y como razón y ciencia han ocupado todo lo que antaño explicaba la mitología: el mundo ha perdido, pues, su alma. Más allá del análisis textual, si el traductor es capaz de identificarse con este mismo sentimiento, podrá acometer su labor con mayor éxito.

\subsection{La traducción de textos dramáticos}

Esta misma premisa resulta válida para la traducción de textos dramáticos y narrativos. En el caso del drama, el traductor ha de ser especialmente cauteloso, pues la obra dramática ha de contemplarse desde

${ }^{13}$ Traducción de la autora. 
la doble cualidad que la define: como obra literaria, y como espectáculo. Es decir, la obra dramática consta no sólo de diálogos entre personajes, sino también de indicaciones sobre el decorado, sobre las actitudes de los personajes para declamar, sobre los sentimientos que han de transmitir, etc. (Merino, 1994: 10-11):

(...) es inevitable referirse a los dos aspectos que definen el género dramático y que van indisolublemente unidos: el teatro como literatura y el teatro como espectáculo; (...) Resulta inevitable pensar que una obra de teatro ha sido o puede ser representada, que su autor la concibió para un escenario. La estructura misma del texto dramático indica que esta dualidad está presente. Al contrario de lo que ocurre en la narrativa o en la poesía, en la pieza dramática la lengua se manifiesta al menos en dos niveles: el diálogo y todo lo que no es diálogo. (...) Cualquier obra de teatro, en mayor o menor medida, utiliza estos dos niveles de lengua y, en ellos, se refleja la doble naturaleza del texto teatral, escrito para ser leído y representado, y la especificidad de este género literario.

Por otro lado, el texto teatral "no es un todo unívoco y existe una gran diversidad de géneros y subgéneros textuales (Hurtado Albir, 2011: 67): comedia, tragedia (griega, humanista, isabelina, francesa clásica, del absurdo, etc.), drama (melodrama, tragicomedia, moralizador, etc.), géneros menores (entremés, farsa, sainete y vodevil)", lo que condiciona, de manera irremediable, la traducción del texto dramático.

Tomemos como referencia el siguiente fragmento, de Turandot, Prinzessin von China, de Friedrich Schiller, en el que podemos observar no sólo el diálogo entre los personajes, sino también las acotaciones en torno a la escena, y la actitud de los personajes que intervienen en ella:

\section{Vierter Auftritt}

Man hört einen Marsch. Truffaldin tritt auf, den Säbel an der Schulter, die Schwarzen hinter ihm; darauf mehrere Sklavinnen, die zu den Trommeln akkompagnieren. Nach diesen Adelma und Zelima, jene in tartarischen Anzug, beide verschleiert. Zelima trägt eins Schüssel mit versiegelten Papieren. Truffaldin und seine Schwarzen werfen sich im Vorbeizien vor dem Kaiser mit er Stirn auf die Erde und stehen sogleich wieder auf, die Sklavinnen knieen niede mit derHand auf der Stirn. Zuletzt erscheint Turandot verschleiert, in reichert chinesischer Kleidung, majestätisch und stolz. Die Räte und Doktoren werfen sich vor ihr mit dem Angesicht auf die Erde, Altoum steht auf, die Prinzessin macht ihm, die Hand auf der Stirn, eine abgemessene Verbeugung, steigt dann auf ihren Thron und setzt sich, Zelima und Adelma nehmen zu ihren beiden Seiten Platz und die letztere den Zuschauern am nächsten. Truffaldin nimmt der Zelima die Schüssel ab 
und verteilt unter lächerlichen Zeremonien die Zettel unter die acht Doktoren. Darauf entfernt er sic mit denselben Verbeugungen wie am Anfang, und der Marsch hört auf.

(...)

TURANDOT. Noch keiner trat Im Diwan auf, der dieses Herz zu rühren Verstanden hätte. Dieser weiß die Kunst.

ZELIMA. Drei leichte Rätsel denn, und Stolz, fahr hin!

TURANDOT. Was sagst du? Wie, Verwegne? Meine Ehre?

(...)

TURANDOT. Prinz! Noch ists Zeit. Gebt das verwegne

Beginnen auf. Gebts auf. Weicht aus dem Diwan.

Der Himmel weiß, daß jene Zungen lügen,

Die mich der Härte zeihn und Grausamkeit.

-lch bin nicht grausam. Frei nur will ich leben

Bloß keines andern will ich sein; dies Recht,

Das auch dem allerniedrigsten der Menschen

Im Leib der Mutter anerschaffen ist,

Will ich behaupten, einer Kaisertochter.

Ich sehe durch ganz Asien das Weib

Erniedrigt, und zum Skavenjoch verdammt,

Und rächen will ich mein beleidigtes Geschlecht

An diesem stolzen Männervolke (...)

(...)

Desde un punto de vista estrictamente lingüístico, existen algunas dificultades, especialmente para el traductor novel, pero que pueden resolverse con una buena labor de documentación. Así, por ejemplo, la sintaxis de las partes dialogadas del texto original exige una detenida lectura para entender de forma clara el significado de cada línea. Pero más allá de cuestiones morfosintácticas o lexicológicas, es necesario que el traductor se identifique con los personajes para poder "ser" ellos, pensar como ellos, "vivir" lo que viven ellos, y por lo tanto, declamar como ellos lo harían. En cierto modo, ha de hacer un ejercicio mental idéntico al que el actor o la actriz deberán hacer antes de representar su personaje. Dicho de otro modo: ha de interiorizar el texto. El traductor, como lector privilegiado, ha de crear la atmósfera que presenta el original: ha de situarse en la China imperial, llena de férreas convenciones y de actitudes misóginas, donde la mujer desempeña un papel extremadamente secundario, y está abocada a obedecer la autoridad paterna, aún siendo la heredera del trono imperial.

En esta situación se encuentra la joven y bella Turandot, que por su noble cuna ha de desposarse con algún pretendiente de sangre real. Decidida a rebelarse contra su destino, y abusando de la nobleza de su anciano padre, el emperador Altoum, consigue que el anciano promulgue 
una ley mediante la cual sólo habrá de desposarse con aquel candidato de noble estirpe que resuelva los tres enigmas que la propia Turandot pronunciará en el Diwan, Consejo Supremo que determinaba los negocios de Estado y de justicia ${ }^{14}$; en caso de no conseguirlo, el desdichado aspirante habrá de pagar con la muerte: morirá decapitado.

Lejos de ser una princesa cruel, como la cree el pueblo, Turandot es un corazón apasionado que intenta sobrevivir en un mundo de hombres, en un patriarcado que la obliga a ser princesa, antes que mujer. $Y$ así lo plasma, con vehemencia, en su discurso:

\section{Escena IV}

Se oye una marcha. Truffaldin entra en escena, con el sable al hombro, le siguen los esclavos negros, $y$, tras ellos, varias esclavas que acompañan a los tamborileros. Tras éstos Adelma y Zelima, ambas ataviadas con traje tártaro, y cubiertas con un velo. Zelima porta una bandeja con documentos lacrados. Trufffaldin y sus esclavos negros se tiran al suelo con la frente sobre el piso al paso del emperador, las esclavas se arrodillan con la mano en la frente. Por último entra Turandot, cubierta con un velo, vestida con lujosos ropajes, con actitud orgullosa y majestuosa. Los Consejeros y los Doctores se tiran al suelo a su paso, con el rostro sobre el piso. Altoum se pone en pie, la princesa le hace una reverencia con la mano en la frente, sube a su trono y toma asiento. Zelima y Adelma ocupan su lugar junto a ella, ésta última más próxima a los presentes en la sala. Truffaldin toma la bandeja que porta Zelima y con un ritual ceremonioso, entre sonrisas, reparte las notas entre los ocho Doctores. Entonces se aleja con la misma reverencia del principio, y la marcha cesa.

TURANDOT. Ningún otro había entrado en el Diván

que pudiese conmover mi corazón.

¡Éste bien sabe cómo hacerlo!

ZELIMA. Pues entonces, Princesa, formulad tres enigmas livianos, $y$ ¡buscad sus brazos!

TURANDOT. ¿Qué dices? ¡Cómo osas, atrevida! ¡Jugar así con mi honor!

(...)

TURANDOT. ¡Príncipe! Aún estáis a tiempo. Abandonad

Tan intrépida osadía. Dejadlo. Salid del Diván.

Los dioses saben que mienten las lenguas

Que me tachan de insensible y cruel

-Yo no soy cruel. Sólo quiero vivir libre.

Ninguna otra cosa ansío; este derecho,

que hasta el más pobre de los hombres ya tiene

\footnotetext{
${ }^{14}$ También se denomina Diwan a la sala donde dicho Consejo se reunía, para impartir justica, o para dirimir asuntos de Estado.
} 


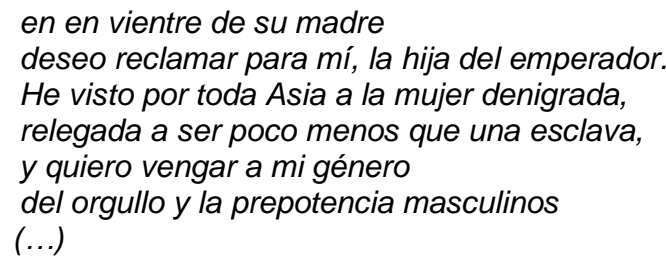

\section{CONCLUSIÓN}

Los ejemplos aquí presentados constituyen una pequeña muestra de cuán difícil puede resultar traducir literatura, especialmente cuando las convenciones lingüísticas y culturales son, en principio, distantes entre la cultura origen y la cultura meta, como es el caso de la traducción alemánespañol. No obstante, y amén de una ardua preparación lingüística, literaria, traductológica, y documental, no debe faltar un ingrediente: el afán de asimilar el texto origen como propio, identificándonos con los sentimientos de los personajes, con el autor y su época, interiorizándolo, y, en definitiva, "levantando la nariz del papel". No en vano, Swetlana Geier, que tuvo la valentía de traducir del ruso — su lengua materna - al alemán — su segunda lengua - la obra de Dostojewskij, afirmaba:

Ich habe mich nie als Übersetzerin gesehen. Auch heute, nach 50 Jahren, nicht. Ich glaube, ich fühle mich einfach als mich selber. Ich lebe gern, ich atme gern. Und Übersetzen ist eine Form zu atmen.

\section{REFERENCIAS BIBLIOGRAFICAS}

BAssnetT, Susan; LefEVERE, André, Constructing Cultures. Essays on Literary Translation. Clevedon, UK: Multilingual Matters Ltd, 1998.

ETTE, Ottmar, "Mit Worten des Anderen. Die literarische Übersetzung als Herausforderung der Literaturwissenschaft“. EN: Armbruster, Claudius \& Karin Hopfe (Hrsg.), Horizont-Verschiebungen: interkulturelles Verstehen und Heterogenität in der Romania. Tübingen: Narr, 1998, pp. 13-33.

Gut, Taja, Swetlana Geier. Ein Leben zwischen den Sprachen. Russichdeutsche Erinnerungsbilder. Dornach: Pforte Verlag, $2011^{5}$.

HELIN, Irmeli, „Gedichtübersetzung und Dialekt - eine unmögliche Kombination?". En: inTRAlinea, online translation journal, 2012. Disponible en:

http://www.intralinea.org/specials/article/gedichtuebersetzung_und_di alekt_eine_unmoegliche_kombination. [Consultado el 20 agosto de 2013].

Holmes, James S., Translated! Papers on Literary Translation Studies. Amsterdam, Atlanta: Rodopi, 1994. 
HuRTADO AlBIR, Amparo, Traducción y traductología. Introducción a la traducción. Madrid: Cátedra, 2011. $5^{\text {a }}$ ed.

Martino AlBa, Pilar, "Un paseo Jeronimiano por la National Gallery de Londres". En: Hieronymus Complutensis 9-10, pp. 189-195.

MERINO ÁlvareZ, R., Traducción, tradición y manipulación. Teatro inglés en España 1950-1990. León: Universidad de León, Universidad del País Vasco, 1994.

NAITO, Mitio, "Einige Bemerkungen zu grundsätzlichen Problemen beim Übersetzen lyrischer Texte". EN: Frank, Armin Paul; Maaß, KurtJürgen; Paul, Fritz et. al. (Hrsg.), Übersetzen, verstehen, Brücken bauen. Geisteswissenschafliches und literarisches Übersetzen im internationalen Kulturaustausch. Berlin: Erich Schmidt, 1993, pp. 516524.

PoltermanN, Andreas, "Normen des literarischen Übersetzens im System der Literatur". En: Kittel, Harald (Hrsg.), Geschichte, System, literarische Übersetzung. Berlin: Erich Schmidt, 1992, pp. 5-31.

REXHeuser, Adelheid, "Die poetische Technik Paul Celans in seinen Übersetzungen russischer Lyrik". En: Arcadia - Internationale Zeitschrift für Literaturwissenschaft 10, 2009, pp. 273-295.

SCHLEIERMACHER, Friedrich; VON MüHLEn POLL, Margarete; BraidA, Celso R.; FURLAN, Mauri, "Über die verschiedenen Methoden des Übersetzens. Traduções sinóticas“. En: Scientia Traductionis 9, 2011, pp. 3-70. 